\title{
Modeling Refractive Index Change in Writing Long-Period Fiber Gratings Using Mid-Infrared Laser Radiation
}

\author{
João M. P. COELHO*, Marta C. NESPEREIRA, Manuel ABREU, \\ and José M. REBORDÃO
}

\author{
University of Lisbon, Faculty of Sciences, Laboratory of Optics, Lasers and Systems, 1749-016 Lisbon, Portugal \\ University of Lisbon, Faculty of Sciences, Institute of Biophysics and Biomedical Engineering, 1649-038 Lisbon, \\ Portugal \\ ${ }^{*}$ Corresponding author: João M. P. COELHO $\quad$ E-mail: joao.coelho@fc.ul.pt
}

\begin{abstract}
The research on the use of fiber sensors based on long-period fiber gratings inscribed by $\mathrm{CO}_{2}$ laser mid-infrared radiation has increased in the last years. In this paper, a set of analytical expressions are used to model the interaction between laser radiation and an optical fiber and to determine the resulting refractive index change. Thermal and residual stress analysis is exemplified for a standard single mode fiber, demonstrating the capability of these models to point out the necessary parameters to achieve proper optical fiber devices based on long period fiber gratings. Experimental results are also presented.
\end{abstract}

Keywords: Optical fiber sensors, fiber gratings, laser processing, refractive index, thermo-mechanical processes

Citation: João M. P. COELHO, Marta C. NESPEREIRA, Manuel ABREU, and José M. REBORDÃO, "Modeling Refractive Index Change in Writing Long-Period Fiber Gratings Using Mid-Infrared Laser Radiation,” Photonic Sensors, vol. 3, no. 1, pp. 67-73, 2013.

\section{Introduction}

Long-period fiber grating (LPFG) sensors are important devices in the field of optical fiber sensors. Comparing with fiber Bragg grating (FBG) sensors (the other "traditional" technology in the field), they have simpler fabrication processes, lower cost, lower retroreflection, higher sensitivity and robustness in sensing applications [1-4]. The LPFG can be considered as a special class of the FBG in which the period of the index modulation, $\Lambda$, satisfies a phase matching condition between the fundamental core mode and a forward propagating cladding mode of an optical fiber:

$$
{ }_{\text {res }}^{m}=\left(n_{\text {eff,co }}-n_{\text {eff,cl }}^{m}\right) \Lambda
$$

where $\lambda_{\text {res }}^{m}$ is the resonant wavelength of light coupling into a particular cladding mode $m, n_{\text {eff,co }}$ and $n_{\text {eff,cl }}^{m}$ are the effective refractive indexes of the core and $m$ th-cladding modes, respectively.

These devices can be produced by generating a periodical perturbation of the refractive indexes in the core, cladding, or both along the length of an optical fiber. While typically the length of an FBG ranges from a few millimeters to about one centimeter with modulation periods of a few dozens of microns, the length of an LPFG is of the order of a few centimeters with periods of hundreds of micrometers.

Although localized mechanical periodic deformation of the fiber [5] and etching of the cladding have been reported [6], the most common methods use electric arc discharges (e.g. [7, 8]) or

Received: 24 July 2012 / Revised version: 8 August 2012

(C) The Author(s) 2012. This article is published with open access at Springerlink.com 
ultra-violet (UV) (e.g. $[9,10])$ or mid-infrared (MIR) radiation (e.g. [11-14]).

The first LPFG was introduced in 1995 by Vengsarkar who exposed photosensitive optical fibers to UV laser light $[9,10]$. This procedure has become usual, either using an amplitude mask (as in the initial work) or point by point (sequential writing). However, the technique is limited to photosensitive fibers and low temperature applications. These drawbacks can be overcome by using a heating source to simultaneously generate a refractive index modulation in the core and cladding, by applying either an electric arc discharge [8] or a MIR laser source [12]. The later technique has better predictability and repeatability when using laser radiation, usually a $\mathrm{CO}_{2}$ laser beam.

The first results of applying $\mathrm{CO}_{2}$ lasers $10.6 \mu \mathrm{m}$ wavelength radiation to produce LPFG were published in 1998 by Davis et al. [11] and Akiyama et al. [12]. In both cases, to write a single period of a grating, radiation was focused to a spot by means of spherical lenses. Spots had dimensions of about 100 microns, and the fiber was submitted to a traction force by use of a weight applied to its end (around $4 \mathrm{~g}$ for Davis and between tenths and hundreds of grams for Akiyama). Translation stages were used to move the laser spot over the fiber. Single-side exposure and symmetric exposure to the laser radiation were compared by $\mathrm{Oh}$ et al. [14], demonstrating that the polarization-dependent loss of the first fabrication method $(1.85 \mathrm{~dB}$ at $1534 \mathrm{~nm})$ could be significantly reduced to $0.21 \mathrm{~dB}$ by applying the second method. Nevertheless, due to its simplicity, the single-side exposure is the most commonly used methodology.

In the following sections, the different thermo-mechanical effects of the interaction between a MIR laser beam and a standard silica-based single mode optical fiber will be analyzed, both theoretically and experimentally.

\section{Thermo-mechanical models}

Considering a standard silica-based optical fiber under tension and irradiated by an elliptical (Gaussian) 10.6- $\mu \mathrm{m}$-wavelength beam emitted from a $\mathrm{CO}_{2}$ laser (Fig. 1), two main phenomena must be considered: the thermal heating due to the interaction between the photons and the glass molecular structure and the stress due to the differences between a relatively low-viscosity doped silica core and a relatively high-viscosity pure silica cladding [15].

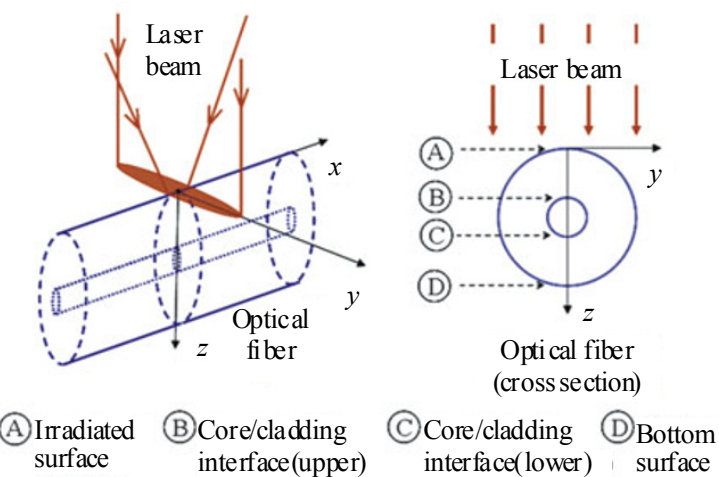

Fig. 1 Schematic of the coordinates referential considered in this work: the $x$-coordinate is coincident with the fiber's axis, and the origin is at the laser beam's central point of incidence on the fiber side.

Differences between the core and cladding thermal expansion coefficients and viscosity lead to residual thermal stresses and draw-induced residual stresses. In the case under study, these effects are localized and, when periodically induced in the fiber's length, can be responsible for the creation of the gratings. This effect is due to the refractive index change resulting from frozen-in viscoelasticity [16].

\subsection{Heat transfer}

Assuming the coordinate system presented in Fig. 1 and neglecting the radiative and surface heat losses as well as the temperature dependence of the properties of the material, the general heat conduction equation can be solved by the Green's function method for an elliptical laser heat source [17-19]. The resultant temperature can be obtained 
through the equation $[17,19]$

$$
\begin{gathered}
T(x, y, z, t)=\frac{(1-R) P}{4 \pi k\left(r_{x} r_{y}\right)} \int_{0}^{\sqrt{K t}} I(x, y, s) . \\
{\left[\exp (\alpha z) \operatorname{erfc}\left(\frac{\alpha s}{2}+\frac{z}{s}\right)+\right.} \\
\left.+\exp (-\alpha z) \operatorname{erfc}\left(\frac{\alpha s}{2}-\frac{z}{s}\right)\right] d s
\end{gathered}
$$

where $R$ is the reflectivity of the fiber's cladding material, $P$ is the incident laser power, $k$ is the thermal diffusivity, $K$ is the thermal conductivity, $\alpha$ is the thermal absorption coefficient, $r_{x}$ and $r_{y}$ are the beam's radii (in $x$ and $y$ coordinates), $t$ is the time, and

$$
\begin{aligned}
& I(x, y, s)=\frac{\alpha s}{\frac{s^{2}}{\left(r_{x} r_{y}\right)}+1} . \\
& \cdot \exp \left[\frac{x^{2}}{r_{x}^{2}+s^{2}}-\frac{y^{2}}{r_{y}^{2}+s^{2}}+\frac{(\alpha s)^{2}}{4}\right] .
\end{aligned}
$$

\subsection{Residual stresses}

With the temperature, $T$, as given by (2), the resultant residual thermal stresses can be calculated using [19]

$$
\sigma_{x}=\frac{E}{1-v}\left[\frac{2 v}{r_{c}^{2}} \int_{r=0}^{r_{c}} \alpha T r d r-\alpha T\right]
$$

where $r_{c}$ is the radius of the cladding or core, $E$ is the Young's modulus, and $v$ is the Poisson's ratio.

The residual axial elastic stresses in the cladding and core, $\sigma_{\mathrm{cl}}$ and $\sigma_{\mathrm{co}}$, respectively, resulting from a draw tension $F$, over the equivalent cross-sectional areas $A_{\mathrm{cl}}$ and $A_{\mathrm{co}}$, can be obtained from [19]

$$
\sigma_{x, \mathrm{cl}}=\frac{F}{A_{\mathrm{cl}}}\left(\frac{A_{\mathrm{co}} E_{\mathrm{co}}}{A_{\mathrm{co}} E_{\mathrm{co}}+A_{\mathrm{cl}} E_{\mathrm{cl}}}\right)
$$

and

$$
\sigma_{x, \mathrm{co}}=F\left(\frac{E_{\mathrm{co}}}{A_{\mathrm{co}} E_{\mathrm{co}}+A_{\mathrm{cl}} E_{\mathrm{cl}}}\right) .
$$

Taking in consideration the mentioned stresses, the refractive index change in a silica-based optical fiber can be approximated by the relation [16]

$$
\Delta n \approx-6.35 \times 10^{-6} \sigma
$$

where $\sigma$ represents the overall (both thermal and drawn-induced) residual stresses (in $\mathrm{MPa}$ ) in the fiber's axial direction. Accordingly with Yablon [15], stresses in the other directions can be neglected.

In the considered case, the fiber is composed of a low viscosity, high thermal expansion coefficient core and a high viscosity, low thermal expansion coefficient cladding, and the drawn-induced axial residual stresses act in opposition to the residual thermal stress. One can therefore be dominant or, alternatively, they can even eliminate each other.

Besides stress-related refractive index change, localized heating can induce microdeformation of the fiber and also changes in the glass structure of the fiber. The later is likely to occur in the core for which the fictive temperature (below the fictive temperature the glass structure doesn't change) is lower [7, 21]. In literature [21], it can be found that, for a Ge-doped core, the fictive temperature ranges from $1150 \mathrm{~K}$ and $1500 \mathrm{~K}$. However, these issues are not addressed in the present work.

\section{Parameters and methodologies}

\subsection{Optical fiber}

The irradiated subject of this study was a standard single-mode fiber, SMF-28 from Corning Inc. [22], consisting of a core of $3.5 \mathrm{~mol} \% \mathrm{Ge}$-doped $\mathrm{SiO}_{2}$ and a pure fused silica cladding. Table 1 presents its main parameters and their references. Values from Yang et al. [17] were considered for the 10.6- $\mu \mathrm{m}$ wavelength of a $\mathrm{CO}_{2}$ laser and equals for both the core and the cladding. This assumption could be made mainly since the Ge concentration in the fiber's core was very low [25-27].

Table 1 Considered optical fiber parameters.

\begin{tabular}{ccc}
\hline Parameter & Core & Cladding \\
\hline Radius, $r(\mu \mathrm{m})[22]$ & 4.1 & 62.5 \\
Refractive index, $n(@ 1550 \mathrm{~nm} ; 300 \mathrm{~K})[26]$ & 1.449 & 1.444 \\
Young's modulus, $E(\mathrm{GPa})[27]$ & 70.8 & 72 \\
Poisson's ratio, $v[27]$ & 0.165 & 0.173 \\
Reflectivity, $R(@ 10.6 \mu \mathrm{m})[17]$ & & 0.15 \\
Density, $\rho\left(\mathrm{kg} / \mathrm{cm}^{3}\right)[17]$ & $2.2 \times 10^{-3}$ \\
Specific heat, $C_{p}(\mathrm{~J} / \mathrm{kg} \cdot \mathrm{K})[17]$ & 703 \\
Thermal conductivity, $k\left(\mathrm{~W} / \mathrm{m}^{2} \cdot \mathrm{K}\right)[17]$ & & 2 \\
Thermal diffusivity, $K\left(\mathrm{~m}^{2} / \mathrm{s}\right)[17]$ & $\mathrm{k} / \rho \cdot C_{p}$ \\
Absorption coefficient, $\alpha\left(\mathrm{cm}^{\square 1}\right)[17]$ & 250 \\
\hline
\end{tabular}




\subsection{Laser parameters}

Figure 2 shows a schematic of the experimental apparatus used for asymmetrical irradiation of the optical fibers. The laser source, was a 10.6- $\mu$ m-wavelength $\mathrm{CO}_{2}$ laser (Synrad 48-2), used with a 50-mm focal length cylindrical lens creating a elliptical beam on the fiber with $r_{x}=0.15 \mathrm{~mm}$ and $r_{y}=1.75 \mathrm{~mm}$. The dimensions of the beam on focus were measured through the knife-edge method [28].

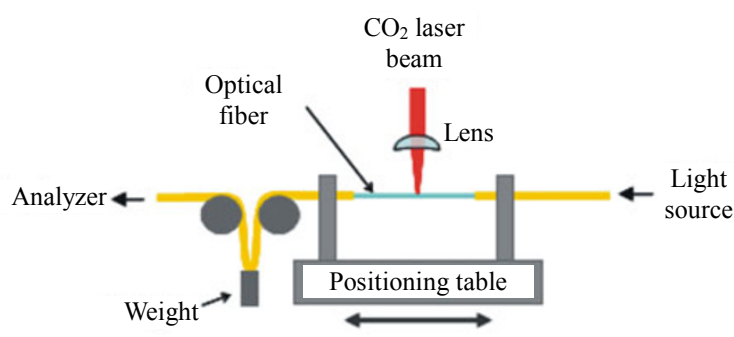

Fig. 2 Schematic of the irradiation setup

The laser radiation was applied for $0.6 \mathrm{~s}$ with a delivered power of $6 \mathrm{~W}$, while the fiber was subjected to a tension of $0.157 \mathrm{~N}$, in practice resultant from fixing one of the ends and hanging a 16-g weight on the other end. The fiber was periodically moved along its axial direction with a translation stage. The experimental apparatus also consisted of a broad band light source (Thorlabs S5FC1005S) and an optical spectrum analyzer (OSA) allowing the monitoring of the LPFG fabrication, while a fast camera (PCO SensiCAM), perpendicular to the irradiation axis, was used to optically visualize the process. The irradiated zones were analyzed using an optical microscope with an amplification up to $1,000 \times$.

\section{Results and analysis}

Figure 3 shows the plots resulting from the simulation using (2) under the conditions mentioned in the previous section for the irradiated front surface, core/cladding interfaces (upper and lower) and the back surface of the fiber (Fig. 1), and $x=y=$ 0 . The time simulated was made higher than the pulse duration so the cooling process could be visualized. Temperature reached around $1250 \mathrm{~K}$ at the interfaces between the core and cladding, and one could assume that the core could be considered as being at the same temperature. This assumption could not be made regarding the cladding since the temperature varied about $200 \mathrm{~K}$ along its thickness.

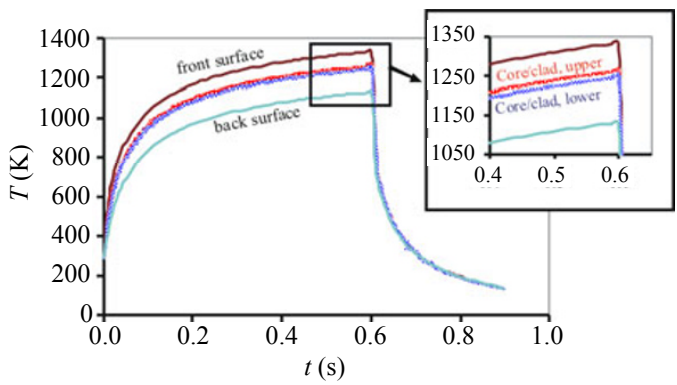

Fig. 3 Plots of the temperature evolution during laser irradiation and cooling: the curves were obtained at the optical fiber's front surface, core/cladding interfaces (upper and lower) and at the back surface of the fiber (Fig. 1), and $x=y=0 \mathrm{~mm}$.

One important issue when considering the possibility of achieving shorter periods is the temperature distribution in the axial direction $(x)$. Figure 4 plots the temperature distribution over the fiber's axial direction for the conditions previously mentioned for Fig. 3 for the duration of the laser emission. This type of analysis can give an

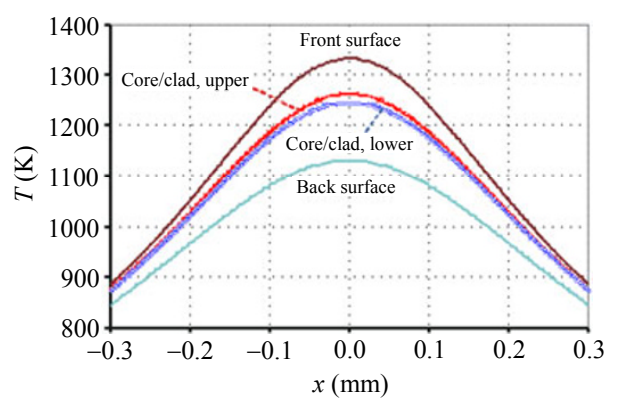

Fig. 4 Temperature distribution at the fiber's axial direction at $t=0.6 \mathrm{~s}$ : the curves were obtained in the same conditions of those of Fig. 3.

indication on the shorter LPFGs period that be accomplished with this method and on the parameters relevant to it. Figure 5 shows the equivalent temperature distribution but for $P=$ $6.6 \mathrm{~W}$ and $0.3-\mathrm{s}$ irradiation time. Then, for similar temperatures, the affected length (in $x$ ) is lower, especially for the interior parts. The same effect can also be accomplished by reducing the beam's radius 
in the fiber's axial direction.

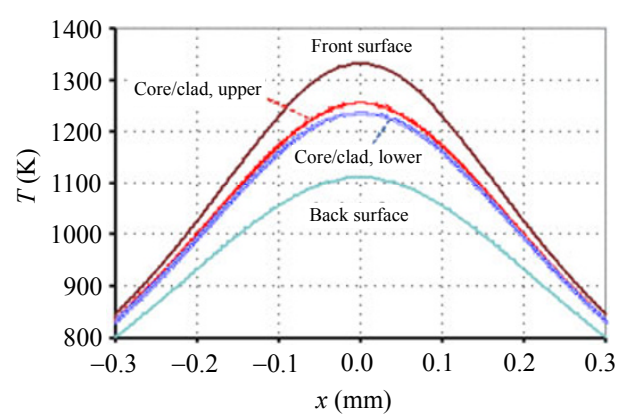

Fig. 5 Plots of the temperature distribution at the fiber's axial direction in the same conditions of those of Fig. 4, but for $P=$ $6.6 \mathrm{~W}$ and $t=0.3 \mathrm{~s}$.

Using (4), (5) and (6), the overall residual stresses can be calculated. For the considered example, expected axial residual thermal stresses (for the core and cladding) are about $-50 \mathrm{MPa}$ (calculated at the core/cladding interfaces), having similar values along $z$. As expected, axial elastic stresses act in the opposite direction: $\sigma_{x, \text { co }}=12.57 \mathrm{MPa}$ and $\sigma_{x, \mathrm{cl}}=0.05 \mathrm{MPa}$. Thus, the resulting refractive index change (the difference between final and initial values) is calculated to be in the order of $2 \times 10^{-4}$ for the core and $3 \times 10^{-4}$ for the cladding (peak induce-index changes of $2.3 \times 10^{-4}$ and $3.4 \times 10^{-4}$, respectively).

Figure 6 shows the values obtained for the mentioned refractive index variation along the fiber's axis $(x)$ at the front surface (cladding), the middle (core) and the back surface (cladding). The resulting refractive index distribution in the fiber ( $y, z$ plane), before and after the laser irradiation is showed in Fig. 7. These values are in agreement with those estimated by other authors (e.g. [7, 29-32]) for the refractive index modulations necessary for achieving a fiber optic grating.

In the previous example, the residual thermal stresses are higher than the elastic stresses. However, if heavier weights are used (increase in the draw tension), this balance changes which also lead to changes in the relation between the initial and irradiated refractive indexes. Since the residual elastic stresses for the cladding are several orders of magnitude lower than those for the core, this effect will occur basically at the core. Accordingly with the considered equations, under the same irradiation conditions, for weights higher than $60 \mathrm{~g}$, the core's refractive index diminishes after irradiation. For this weight, the refractive index modulation in the fiber is basically accomplished at the cladding.

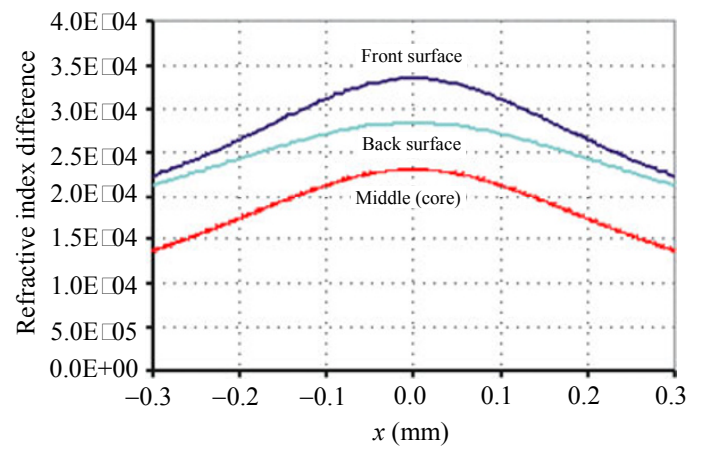

Fig. 6 Plots of the fiber's axial direction refractive index change at the front and back surfaces, and at the middle, for the conditions considered in this work.

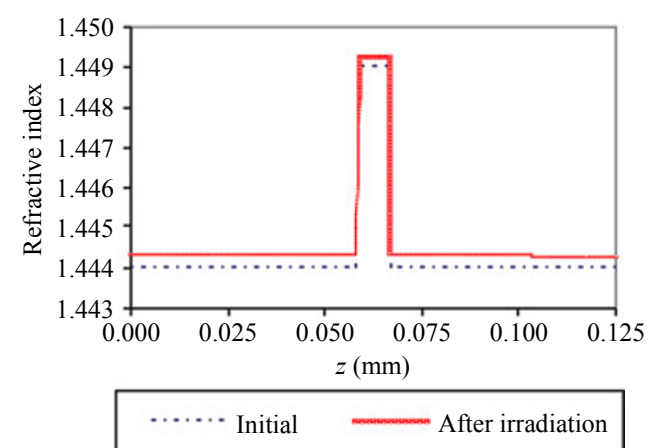

Fig. 7 Calculated refractive index profiles of the fiber, for the conditions considered, before and after laser irradiation.

Figure 8 shows a microscope photo of an irradiated fiber under the conditions considered in this work. This zone was part of a $25-\mathrm{mm}$ grating with a period of $500 \mu \mathrm{m}$, and the visible affected area along the fiber's axis was about $130 \mu \mathrm{m}$. Also visible was a (small) micrometric deformation of the fiber.

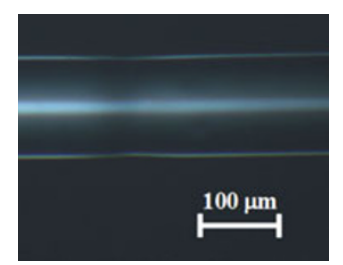

Fig. 8 Picture showing an irradiated area under the conditions considered in this work. 
Analyzing both theoretical (Fig. 4) and experimental data (Fig. 8), one can consider that it is necessary to reach temperatures higher than $1100 \mathrm{~K}$ to accomplish an LPFG under these conditions. This assumption relies on the cross-analysis between the visible affected length of the fiber (around $130 \mu \mathrm{m}$ ) and the fiber's back surface temperature for $x=$ $-65 \mu \mathrm{m}$ or $x=65 \mu \mathrm{m}$. However, additional work should be performed to further validate this analysis and assess which temperatures (and where) are relevant.

\section{Conclusions}

The set of analytical expression presented in this work demonstrated its potential to determine the necessary experimental parameters for obtaining the required refractive index change when writing LPFG by $\mathrm{CO}_{2}$ laser radiation. Naturally, since these expressions did not consider all the physical phenomena (e.g. convection and radiation losses) and were developed assuming several simplifications (mainly, not considering the temperature dependence of the glass parameters), results must be carefully interpreted. Nevertheless, comparing the refractive index change values predicted by these expressions and those considered by other authors for the LPFG, give a good indication on their capability of being used as an engineering tool to develop fiber optic sensors.

Future work will focus on continuing the experimental validation of these results and determining the effective limitations of these models.

\section{Acknowledgment}

This work was partially supported by the Portuguese Fundação para a Ciência e Tecnologia (FCT) through the project PTDC/FIS/119027/2010.

The authors gratefully acknowledge José Luis Santos, Orlando Frazão and Pedro Jorge from INESC-Porto and Catarina Silva for their advices and crucial contributions. A special thanks to
Fernando Monteiro and António Oliveira for their technical support to the activities described in this paper.

Open Access This article is distributed under the terms of the Creative Commons Attribution License which permits any use, distribution, and reproduction in any medium, provided the original author(s) and source are credited.

\section{References}

[1] A. D. Kersey, M. A. Davis, J. P. Heather, M. LeBlanc, K. P. Koo, C. G. Askins, et al., "Fiber grating sensors," Journal of Lightwave Technology, vol. 15, no. 8, pp. 1442-14463, 1997.

[2] C. Silva, J. M. P. Coelho, P. Caldas, O. Frazão, P. A. Jorge, and J. L. Santos, "Optical fiber sensing system based on long-period gratings for remote refractive index measurement in aqueous environments," Fiber and Integrated Optics, vol. 29, no. 3, pp. 160-169, 2009.

[3] A. Martinez-Rios, D. Monzon-Hernandez, Ismael Torres-Gomez, and G. Salceda-Delgado, "Long period fiber gratings," in Fiber Optic Sensors. Moh. Yasin, S. Harun and H. Arof, Ed. Ridjeka, Croatia: InTech, pp. 275-291, 2012.

[4] C. Silva, J. M. P. Coelho, P. Caldas, and P. Jorge, "Fiber sensing system based on long-period gratings for monitoring aqueous environments," in Fiber Optic Sensors. Moh. Yasin, S. Harun and H. Arof, Ed. Ridjeka, Croatia: InTech, pp. 317-341, 2012.

[5] S. Savin, M. J. F. Digonnet, G. S. Kino, and H. J. Shaw, "Tunable mechanically induced long-period fiber gratings," Optics Letters, vol. 25, no. 10, pp. 710-712, 2000.

[6] M. Vaziri and C. L. Chen, "An etched two-mode fiber modal coupling element," Journal of Lightwave Technology, vol. 15, no. 3, pp. 474-481, 1997.

[7] G. M. Rego, "Arc-induced long-period fiber gratings: fabrication and their application in communications and sensing," Ph. D. dissertation, Dept. Elect. Comp. Eng., Univ. of Porto, Porto, Portugal, 2006.

[8] J. Estudillo-Ayala, R. Mata-Chavez, J. Hernandez-Garcia, and R. Rojas-Laguna, "Long period fiber grating produced by arc discharges," in Fiber Optic Sensors. Moh. Yasin, S. Harun and H. Arof, Ed. Ridjeka, Croatia: InTech, pp. 295-316, 2012.

[9] A. M. Vengsarkar, P. J. Lemaire, J. B. Judkins, B. Bhatia, T. Erdogan, and J. E. Sipe, "Long-period fiber gratings as band-rejection filters," in Optical 
Fiber Communication Conference (OFC), San Diego, CA, Feb. 1995, pp. PD4-2, 1995.

[10] A. M. Vengsarkar, P. J. Lemaire, J. B. Judkins, V. Bhatia, T. Erdogan, and J. E. Sipe, "Long-period fiber gratings as band-rejection filters," Journal of Lightwave Technology, vol. 14, no. 1, pp 58-65, 1996.

[11] D. D. Davis, T. K. Gaylord, E. N. Glytis, S. G. Kosinski, S. C. Mettler, and A. M. Vengsarkar, "Long period fiber grating fabrication with focused $\mathrm{CO}_{2}$ laser pulses," Electronics Letters, vol. 34, no. 3, pp. 302-303, 1998.

[12] M. Akiyama, K. Nishide, K. Shima, A. Wada, and R. Yamauchi, "A novel long-period fiber grating using periodically releases residual stress of pure-silica core fiber," in Optical Fiber Communication Conference (OFC), San José, CA, Feb. 22-27, pp. 276-277, 1998.

[13] J. Coelho, M. Nespereira, C. Silva, and J. Rebordão, "LOLS research in technology for the development and application of new fiber-based sensors," Sensors, vol. 12, no. 3, pp. 2654-2666, 2012.

[14] S. T. Oh, W. T. Han, U. C. Paek, and Y. Chung, "Azimuthally symmetric long-period fiber gratings fabricated with $\mathrm{CO}_{2}$ laser," Microwave Optical Technology Letters, vol. 41, no. 3, pp. 188-190, 2004.

[15] A. D. Yablon, "Optical and mechanical effects of frozen-in stresses and strains in optical fibers," IEEE Journal of Selected Topics in Quantum Electronics, vol. 10, no. 2, pp. 300-311, 2004.

[16] A. D. Yablon, M. F. Yan, P. Wisk, F. V. DiMarcello, J. W. Fleming, W. A. Reed, et al., "Refractive index perturbations in optical fibers resulting from frozen-in viscoelasticity," Applied Physics Letters, vol. 84, no. 1, pp. 19-21, 2004.

[17] S. Yang, M. Matthews, S. Elhadj, V. Draggoo, and S. Bisson, "Thermal transport in $\mathrm{CO}_{2}$ laser irradiated fused silica: in situ measurements and analysis," Journal of Applied Physics, vol. 106, no. 10, pp. 103106-1-103106-7, 2009.

[18] J. Coelho, M. Abreu, and F. Carvalho-Rodrigues, "Modelling the spot shape influence on high-speed transmission lap welding of thermoplastics films," Optics Laser in Engineering, vol. 46, no. 1, pp. 55-61, 2008.

[19] A. Grellier, N. Zayer, and C. Pannell, "Heat transfer modelling in $\mathrm{CO}_{2}$ laser processing of optical fibers," Optics Communication, vol. 152, no. 4-6, pp. 324-328, 1998.

[20] S. P. Timoshenko and J. N. Goodier, Theory of elasticity, 2nd Edition. New York: McGraw-Hill, pp.
409-410, 1951.

[21] M. Lancry, E. Réginier, and B. Poumellec, "Fictive temperature in silica-based glasses and its application to optical fiber manufacturing," Progress in Material Sciences, vol. 57, no. 1, pp. 63-94, 2012.

[22] Corning ${ }^{\circledR}$ SMF-28 optical fiber product information, Corning Inc.: NY, PI1036, 2002.

[23] C. A. Worrel, "Infrared optical constants for $\mathrm{CO}_{2}$ laser waveguide materials," Journal Materials Science, vol. 21, no. 3, pp. 781-787, 1986.

[24] P. D. Dragic, "The acoustic velocity of Ge-doped silica fibers: a comparison of two models," International Journal of Applied Glass Science, vol. 1, no. 3, pp. 330-337, 2010.

[25] P. André, A. Rocha, F. Domingues, and M. Facão, "Thermal effects in optical fibers," in Developments in Heat Transfer. Marco Aurélio dos Santos Bernardes Ed. Ridjeka, Croatia: InTech, pp. 1-20, 2011.

[26] D. Nikogosyan, "Multi-photon high-excitation energy approach to fiber grating inscription," Measurement Science and Technology, vol. 18, no. 1, pp. R1-R29, 2006.

[27] J. Clowes, S. Syngellakis, and M. Zervas, "Pressure sensitivity of side-hole optical fiber sensors," IEEE Photonics Technology Letters, vol. 10, no. 6, pp. 857-859, 2009.

[28] A. E. Siegman, M. W. Sasnett, and T. F. Johnston, "Choice of clip level for beam width measurements using knife-edge techniques," IEEE Journal of Quantum Electronics, vol. 27, no. 4, pp. 1098-1104, 1991.

[29] H. Limberger, P. Y. Fonjallaz, R. Salathé, and F. Couché, "Compaction- and photoelastic-induced index changes in fiber Bragg gratings," Applied Physics Letters, vol. 68, no. 22, pp. 2069-3071, 1996.

[30] X. liu, M. Yan, L. Zhan, S. Luo, Z. Zhang, and Y. Xia, "Controlling of symmetric and asymmetric mode coupling in long-period fiber gratings singe-side induced by long-pulse $\mathrm{CO}_{2}$ laser," Optical Communication, vol. 284, no. 5, pp. 1232-1237, 2011.

[31] T. Erdogan, "Cladding-mode resonances in shortand long-period fiber grating filters," Journal of Optics Society America A, vol. 14, no. 8, pp. 1760-1773 1997.

[32] T. Erdogan, "Cladding-mode resonances in shortand long-period fiber grating filters: errata," Journal of Optics Society America A, vol. 17, no. 11, pp. 2113, 2000. 